\title{
Translation, cross-cultural adaptation and validation of the Pulmonary Rehabilitation Adapted Index of Self-efficacy (PRAISE) scale for Brazilian patients with chronic obstructive pulmonary disease
}

Simone Graciosa Gavenda ${ }^{1,2}$ (1); Manuela Karloh ${ }^{1,2,3}$ (1); Hellen Fontão Alexandre ${ }^{1,2}$ (1); Thiago Sousa Matias ${ }^{4}$ (1); Anamaria Fleig Mayer ${ }^{1,2,5 *}$ (1)

\begin{abstract}
Background: Patients with Chronic Obstructive Pulmonary Disease (COPD) present a progressive chronic airflow obstruction. Pulmonary Rehabilitation (PR) promotes the reversal of the extrapulmonary effects of the disease and improves the quality of life. Despite the physiological benefits, the major challenge of PR is to promote change in lifestyle. In this sense, it has been emphasized the study of psychological variables such as self-efficacy. Aim: To translate, cross-culturally adapt and validate the PRAISE scale for Brazilian COPD patients. Methods: The PRAISE scale was applied on the first day by two raters and 15-20 days later by one rater. Patients were assessed for self-efficacy with the General Self-Efficacy Scale (GSS) and the COPD Self-Efficacy Scale (CSES); functional limitation for activities of daily living with the London Chest Activity of Daily Living (LCADL) scale; anxiety and depression symptoms with the Hospital Anxiety and Depression Scale (HADS); quality of life with Saint George's Respiratory Questionnaire (SGRQ); resilience with the Resilience Scale; and basic psychological needs with the Basic Psychological Needs in Exercise Scale (BPNES). The tests used were: Student's t-test or Wilcoxon's test (PRAISE score comparison); intraclass correlation coefficient (ICC), interrater reliability and test-retest and Cronbach's alpha; and Spearman's or Pearson's correlation coefficient to assess validity. Results: The scale was pre-tested in 10 patients to evaluate translation accuracy and cross-cultural adaptation. Thirty-four patients with COPD took part ( 22 men; $\mathrm{FEV}_{1}=42.2 \pm 15.7 \%$ pred). The interrater and test-retest ICCs were excellent ( 0.82 and 0.86 , respectively), with no significant differences in test-retest reliability $(p>0.05)$. Cronbach's alpha interrater and testretest were 0.90 and 0.92 , respectively $(p<0.001)$. There were no floor and ceiling effects. The scale showed weak to moderate correlations with GSS, CSES, LCADL, HADS, SGRQ, Resilience Scale, and BPNES. Conclusions: The PRAISE scale proved to be valid and reliable for Brazilian patients with COPD.
\end{abstract}

Keywords: Self-efficacy; Chronic Obstructive Pulmonary Disease; Validity.

\section{How to cite}

Gavenda SG, Karloh M, Alexandre HF, Matias TS, Mayer AF. Translation, crosscultural adaptation and validation of the Pulmonary Rehabilitation Adapted Index of Self-efficacy (PRAISE) scale for brazilian patients with chronic obstructive pulmonary disease. Cardiorespir Physiother Crit Care Rehabil. 2021;1: e43048. https://doi. org/10.4322/2675-9977.cpcr.43048

\section{How can the results of this study be used in clinical practice?}

- The test-retest and the inter-rater reliability and internal consistency of PRAISE are excellent.

- The PRAISE is valid and reliable to assess self-efficacy in PR in Brazilians with COPD.

\footnotetext{
Submitted: March 30, 2021

Accepted: October 26, 2021

Study conducted at: Universidade do Estado de Santa Catarina - UDESC, Florianópolis, SC Brasil.

Ethical approval: The study was approved by the local ethics committee (CAEE

39702214.6.0000.0118).

\section{Anamaria Fleig Mayer}

Florianópolis (SC), Brasil

Tel: +55 (48) 3664-8608

- UDESC, Núcleo de Assistência, Ensino -

Universidade do Estado de Santa Catarina Fisioterapia, Florianópolis, SC, Brasil de Santa Catarina Universidade do Estado de Santa Catarin do Esporte, Programa de Pós-graduação em Ciências do Movimento Humano,

E-mail: anamaria.mayer@udesc.br
} unrestricted non-commercial use, distribution, and reproduction in any medium provided the original work is properly cited and is not represented as endorsing the use made of the work. Further, any new works must be made 


\section{Introduction}

The systemic manifestations of Chronic Obstructive Pulmonary Disease (COPD) are well known and extensively documented $^{1}$. In addition to the physical impact, patients deal with the negative consequences of psycho-emotional disorders ${ }^{2}$. This leads to poor adherence to healthy lifestyle habits, such as physical activity ${ }^{3}$. It is well established that physical inactivity contributes to the occurrence of episodes of exacerbation and increased risk of death; therefore, pulmonary rehabilitation (PR) programs combine physical training and education components, and aim to promote behavior change in patients with $\mathrm{COPD}^{3,4}$.

There is some evidence that self-management increases knowledge and skills of patients with COPD; it also improves self-efficacy, i.e., the patients' confidence in their ability to lead and manage self-care ${ }^{3,5,6}$. Self-efficacy influences which activities or situations the patient will perform or avoid, and facilitates the maintenance of behavioral changes acquired during $\mathrm{PR}^{6-8}$.

In connection with physical activity, self-efficacy reflects self-confidence in engaging in, starting and sustaining a given activity ${ }^{9}$. Moreover, self-efficacy is considered a predictor for regular physical activity ${ }^{10}$ and is positively correlated with greater tolerance to physical activity ${ }^{11}$. In this context, evaluating self-efficacy of patients with COPD in PR programs will provide better understanding of the patient's behavior towards the intervention ${ }^{8}$.

PR staff should be able to design rehabilitation programs aiming to support patient's psychological needs by promoting pro-environmental behaviors for self-efficacy/motivational changes, intentionally designed according to the patients' baseline characteristics. The intervention approaches must include the varying self-efficacy profiles of the population ${ }^{12}$. The Pulmonary Rehabilitation Adapted Index of Self-Efficacy (PRAISE) scale, which assesses patients' self-efficacy in $\mathrm{PR}^{13}$, can be pointed out as a valuable tool. The scale has valid and reliable versions available in English ${ }^{13}$, European Portuguese ${ }^{14}$ and Korean ${ }^{15}$. Recently, Liacos et al. ${ }^{16}$ have estimated the minimal important difference (MID) of the tool between 0.5 and 1.5 points, and reported that the post-PR score had an effect size of 0.21. Also, the PRAISE baseline score was considered an independent predictor of change in sedentary behavior after $\mathrm{PR}^{16}$.

However, to date, PRAISE has not been cross-culturally adapted and validated for use in Brazil. Given the need for a specific tool to assess self-efficacy within PR context, the aims of the present study were to translate the PRAISE scale into Brazilian Portuguese, cross-culturally adapt the version and to investigate its measurement properties in patients with COPD.

\section{Methods}

This study was approved by the Ethics Committee of the State University of Santa Catarina (CEP/UDESC) (CAEE 39702214.6.0000.0118). All participants signed the free and informed consent form. The protocol was conducted according to standardized guidelines for the translation and cross-cultural adaptation process ${ }^{17}$ and to the Consensusbased Standards for the Selection of Health Measurement Instruments (COSMIN) ${ }^{18}$.

Patients with COPD referred to the Center for Assistance, Teaching and Research in PR (NuReab) at the Center for Health and Sports Sciences at the Santa Catarina State University (CEFID/UDESC) were recruited. Inclusion criteria were: patients with clinical diagnosis of COPD with a spirometric classification II-IV, according to the Global Initiative for Chronic Obstructive Lung Disease (GOLD) criteria; patients able to read self-reported questionnaires in Portuguese; clinically stable four weeks prior to the administration of the questionnaire; and no hospitalization in the past 12 weeks. The exclusion criteria were: presence of other disorders that might affect the patient's ability to understand the questionnaire or influence the performance of one of the phases of the study; and current smoking or smoking cessation six months prior to the first study evaluation.

\section{Translation and cross-cultural adaptation of the PRAISE scale}

The first author of the original version of the scale (Ms. Emma Vincent) gave written consent for the translation and cross-cultural adaptation process. Afterwards, the scale was translated in two phases: First, the original version of the PRAISE scale was translated from English into Brazilian Portuguese by two independent translators. One of the authors compared the translations and reconciled any meaningful differences to produce and approve one version in Brazilian Portuguese. Next, the approved version was back translated by a native speaker of the English language, with proficiency in Brazilian Portuguese, and without previous involvement with the tool and the present study. The back-translation was sent to the author of the original version (Ms. Emma Vincent), who approved the Brazilian Portuguese version. Ultimately, the version of the PRAISE scale was pre-tested in 10 patients with COPD, in order to identify possible questions and misunderstandings. These patients participated only in this phase of the process. The version did not require any adaptations. Therefore, the final version of the scale translated into Brazilian Portuguese could be applied to the study sample ${ }^{17}$.

\section{Data collection}

The final version of the PRAISE scale was administered at two moments, as an interview between rater and patient. On day 1, it was administered twice by two raters: first by rater 1 (R1) followed by rater 2 (R2-1), within a 30-minute period, with a 5 minutes tolerance. On day 2, rater 2 (R2-2) administered the scale again 15 to 20 days after day 1 . The PRAISE scale is a valid and reliable tool to assess patients' self-efficacy in PR. It has 15 items, 10 from the General Self- 
efficacy Scale and 5 (items 4, 7, 9, 12 and 15) that address specific challenges faced by patients in the context of PR, such as the ability to deal with exercises and with the lung disease. Each item can be scored from 1 to 4 points. The sum of the items yields the final score ranging from 15 to 60 points. Higher scores indicate higher perceived self-efficacy ${ }^{13}$.

Self-efficacy was assessed by other two instruments. The General Self-Efficacy Scale (GSS) assesses a general sense of perceived self-efficacy ${ }^{19}$ and consists of 10 items. The sum of the answers yields the final score that varies between 10 and 40 points. Higher scores indicate higher self-efficacy ${ }^{20}$. COPD Self-Efficacy Scale (CSES) measures self-efficacy of patients with COPD in managing dyspnea or avoiding breathing difficulties during certain activities. It comprehends 34 items categorized into five domains. Higher scores correspond to greater confidence in the management and control of the disease and symptoms ${ }^{21}$.

Besides self-efficacy, other assessments were performed during the study protocol to characterize patients and to better reflect the complexity of self-efficacy. To assess lung function, spirometry was performed using the EasyOne portable spirometer. The methods and criteria followed the recommendations of ATS/ERS ${ }^{22}$. The predicted values were calculated based on the equations proposed by Pereira et $\mathrm{al}^{23}$.

The Saint George's Respiratory Questionnaire (SGRQ) assesses health-related quality of life in patients with $\mathrm{COPD}^{24}$. The Brazilian version contains 76 items measuring three domains: Symptoms, Activities and Impacts ${ }^{25}$. Higher scores indicate worse quality of life and values above $10 \%$ represent impairment in quality of life $\mathrm{e}^{26}$.

The London Chest Activity of Daily Living (LCADL) scale measures limitation in activities of daily living (ADLs) in patients with $\mathrm{COPD}^{27}$. It has been translated into Brazilian Portuguese and validated in Brazil ${ }^{28}$, and consists of 15 questions. Patients score from 0 to 5 for a total of 0 to 75 points. The scale can be analyzed as a percentage of the total score $\left(\mathrm{LCADL}_{\text {total }}\right)$. Higher scores represent maximal limitation to perform ADLs ${ }^{28}$.

The Hospital Anxiety and Depression Scale (HADS) evaluates the presence of symptoms of anxiety and depression. It comprises 14 multiple choice questions, divided into two subscales ${ }^{29}$. Scores $\geq 8$ indicate significant clinical symptoms for anxiety. Scores $\geq 5$ specifies significant clinical symptoms of depression ${ }^{30}$.

The Basic Psychological Needs in Exercise Scale (BPNES) evaluates the patients' perceptions of meeting basic psychological needs as well as their satisfaction with exercise. It consists of 11 items divided into three domains: Autonomy, Relatedness and Competence ${ }^{31}$.

The Resilience Scale measures levels of positive psychosocial adaptation to important life events. It has been validated for the Brazilian population ${ }^{32}$. Given a range of 25 and 175 points, scores up to 125 represent low resilience; between 125 and 145 a moderate resilience; and above 145 a high resilience ${ }^{12}$.

\section{Data analysis}

The data were processed in the SPSS version 20.0 program and presented as mean, standard deviation and $95 \%$ confidence interval or median and interquartile range. The normality of the data was verified by the Shapiro Wilk test and the level of statistical significance was 5\%. The Student's $t$-test for paired samples or Wilcoxon's test was used to compare scores at the PRAISE inter-rater scale and test-retest. The intraclass correlation coefficient was used to assess the reliability of the PRAISE scale (interrater reproducibility and test-retest), and the Cronbach's alpha to measure internal consistency. The Bland-Altman plot was used to analyze the agreement between the scale applications. The validity of the PRAISE scale was assessed by the Spearman's or Pearson's correlation coefficient, using GSS, CSES, SGRQ, BPNES, LCADL, HADS and the Resilience Scale.

The sample size estimation was based on two assumptions: I) expected effect sizes of ICC, Cronbach's alpha and correlation coefficient; and II) COSMIN recommendation of at least 30 participants in order to be considered a fair sample size. It was considered for the estimations: a two-tailed significance level of 0.05 , a power of $90 \%$ and a dropout rate of $20 \%$. Considering 0.70 as the minimum acceptable ICC, the estimated sample size was 19 patients. For a minimum acceptable Cronbach's alpha of 0.70 the estimated sample size was 29 patients. At last, considering an expected correlation coefficient of at least 0.50 , the estimated sample size was 34 patients. The estimation that attended COSMIN recommendation with the highest sample size was used in this study.

\section{Results}

Thirty-eight patients were included in the study and four of them were excluded: two patients had cognitive impairment, one patient had other associated lung diseases, and one patient showed $\mathrm{FEV}_{1} / \mathrm{FVC}$ ratio $>0.7$ in spirometry. Thus, $34 \mathrm{COPD}$ patients (22 men, 64.7\%) completed the study protocol, and their characteristics are described in table 1. Eight patients (23.5\%) were classified as GOLD II, 19 (55.9\%) as GOLD III, and $7(20.6 \%)$ as GOLD IV.

The median difference (interquartile range) in the PRAISE inter-rater score was $0.00(3.00$ to -2.00$)$ and in the test-retest score was 0.00 (2.00 to -2.25$)$. There were no significant differences when comparing the scores of the PRAISE scale in the test-retest analysis ( $p>0.05)$. Floor (15 points) and ceiling effects (60 points) were not observed in any of the three evaluations of the PRAISE scale (Table 2). The minimum time to administer the scale was two minutes and the maximum was nine minutes.

\section{Reliability}

High internal consistency and high reproducibility of the total score of the PRAISE scale were observed in all assessments of the study. Inter-rater Cronbach's alpha of the 
PRAISE scale was 0.90. Cronbach's alpha coefficient for the PRAISE items ranged from 0.60 to 0.86 in the analysis of the inter-rater internal consistency. In the inter-rater reliability analysis, the overall ICC was $0.82(95 \%$ CI $0.67-0.91, \mathrm{p}<0.01)$ and the ICC of the items ranged from 0.43 to 0.76 . The reliability of the items was moderate in all items, except for item 15, which showed high reliability.

Table 1. Sample characteristics.

\begin{tabular}{lc}
\hline Variable & Mean \pm Standard Deviation \\
\hline Age, years & $68.1 \pm 7.49$ \\
Body Mass, Kg & $67.5 \pm 17.4$ \\
Height, $m$ & $1.65 \pm 0.11$ \\
BMI, Kg/m ${ }^{2}$ & $24.5 \pm 4.63$ \\
FEV $_{1} /$ FVC & $0.48 \pm 0.11$ \\
FEV, L & $1.23 \pm 0.55$ \\
FEV, \%pred & $42.2 \pm 15.7$ \\
FVC, L* & $2.22(1.99-2.97)$ \\
FVC, \%pred & $68.0 \pm 17.7$ \\
LCADL Total* & $16.0(13.0-21.2)$ \\
LCADL, \%Total* & $26.0(22.6-30.9)$ \\
SGRQ, Symptoms & $29.9 \pm 20.7$ \\
SGRQ, Activities & $57.7 \pm 19.1$ \\
SGRQ, Impacts* & $20.4(12.0-34.9)$ \\
SGRQ, Total* & $35.7(21.5-40.5)$ \\
HADS, Anxiety & $5.68 \pm 4.21$ \\
HADS, Depression & $4.21 \pm 3.07$ \\
HADS, Total* & $9.00(5.75-13.0)$ \\
Resilience Scale & $141.1 \pm 14.1$ \\
BPNES, Autonomy & $13.3 \pm 3.82$ \\
BPNES, Competence & $14.2 \pm 3.67$ \\
BPNES, Relatedness & $12.3 \pm 2.98$ \\
\hline & \\
\hline
\end{tabular}

Data presented as mean \pm standard deviation except where indicated; *: median (interquartile range); F: female; M: male; Kg: kilogram; m: meters; BMI: body mass index; $\mathrm{FEV}_{1}$ : forced expiratory volume in the first second; $\mathrm{FVC}$ : forced vital capacity; L: liter; \% pred: percentage of the predicted value; LCADL: Activity of Daily Living scale; SGRQ: Saint George's Respiratory Questionnaire; HADS: Hospital Anxiety and Depression Scale; BPNES: Basic Psychological Needs in Exercise Scale.
Test-retest internal consistency of the PRAISE scale was 0.92. Items' Cronbach's alpha coefficient ranged from 0.28 to 0.89 . In the analysis of test-retest reliability, the PRAISE scale ICC was $0.86(95 \%$ CI $0.73-0.93, \mathrm{p}<0.01)$ and the ICC of the items ranged from 0.34 to 0.80 . The reliability of items 2 and 8 were not statistically significant $(p>0.05)$. The reliability was low in items 7 and 12; moderate in items 1, 3, 4, 6, 9, 10, 11, 13 and 15; and high in item 14. The standard error of measurement was 2.43 and the minimum detectable difference was 6.73 points.

Figure 1 shows the inter-rater and test-retest agreement between administrations of the scale. The mean difference between applications was very close to zero and the vast majority of patients were concentrated close to the average of the differences. In addition, it can be seen that no patient scored less than 30 points in the individual mean of the scale's applications.

\section{Validity}

The score obtained at the PRAISE scale showed a moderate correlation with the score obtained at GSS $(r=0.67$; $\mathrm{p}<0.05)$ and a weak correlation with the CSES $(\mathrm{r}=0.34$; $\mathrm{p}<0.05$ ) (Figure 2).

PRAISE also showed weak correlations with the Autonomy and Competence domains of the BPNES scale and with the LCADL $\%_{\text {total }}$ scale, as well as to moderate correlations with the Resilience Scale, HADS and SGRQ (Figure 3). Other correlations that varied from weak to moderate were observed between the PRAISE scale and the $\mathrm{LCADL}_{\text {Physical Activities }}$ scale $(\mathrm{r}=-0.36 ; \mathrm{p}=0.03) ; \mathrm{LCADL}_{\text {Leisure Activities }}(\mathrm{r}=-0.43 ; \mathrm{p}=0.01)$; $\mathrm{SGRQ}_{\text {Impacts }}(\mathrm{r}=-0.44 ; \mathrm{p}<0.01) ; \operatorname{HADS}_{\text {Anxiety }}(\mathrm{r}=-0.35 ; \mathrm{p}=0.04)$; $\operatorname{HADS}_{\text {Depression }}(\mathrm{r}=-0.45 ; \mathrm{p}<0.01) \operatorname{CSES}_{\text {Negative Affect }}(\mathrm{r}=0.39$; $\mathrm{p}=0.02)$. There were no correlations between the PRAISE score and the other studied variables.

\section{Discussion}

The PRAISE scale showed, in the present study, excellent reliability and internal consistency. It is noteworthy that this result is in line with previous data from the original version of the scale, which showed reproducibility of 0.72 (95\% CI, $2.27-$ 0.82 ), and internal consistency of $0.95^{13}$. In the present study, the PRAISE scale did not have any floor nor ceiling effects. This is an important finding, as these effects may interfere

Table 2. Total score, minimum and maximum score values, and application time for the PRAISE scale.

\begin{tabular}{lccc}
\hline & R1 & R2-1 & R2-2 \\
\hline Score & $49(43-54)$ & $51(42-53)$ & 34 \\
Minimum Score & 33 & 58 & \\
Maximum Score & 56 & $54-54)$ \\
Time, minutes & $4.00(3.12-5.00)$ & $2.88(2.62-3.90)$ & $3.13(2.75-4.00)$
\end{tabular}

Data presented as median (interquartile range); R1: rater 1, assessment 1; R2-1: rater 2, assessment 1; R2-2: rater 2, assessment 2. 
A

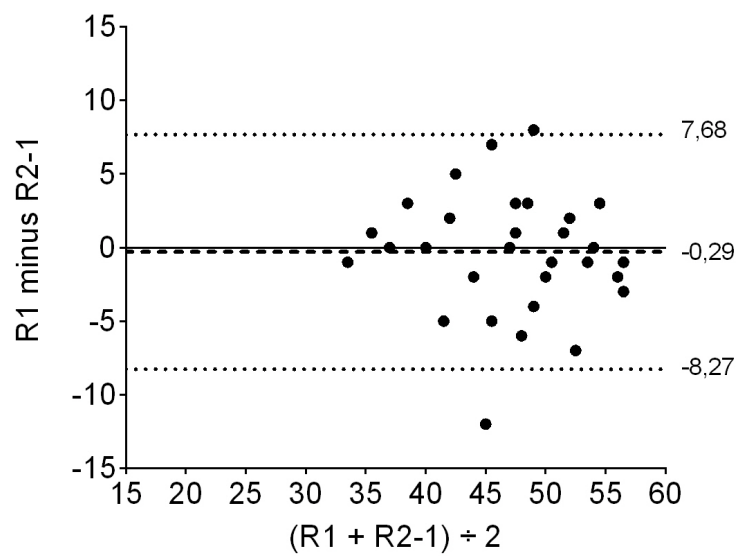

B

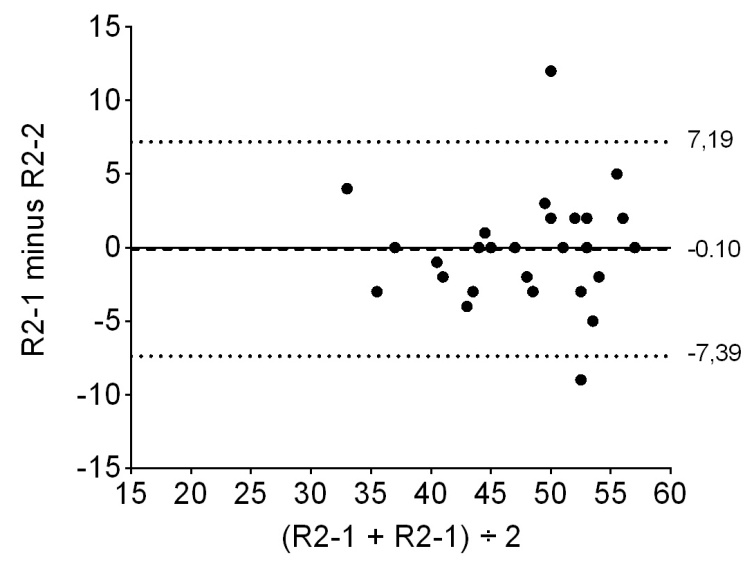

Figure 1. Bland-Altman plots analyzing the agreement between the applications of the PRAISE scale. A: inter-rater agreement. B: testretest agreement. Hatched line: average of the differences; Dotted lines: upper and lower agreement limits (2 standard deviations); R1: rater 1 on day 1; R2-1: rater 2 on day 1; R2-2; rater 2 on day 2).

A

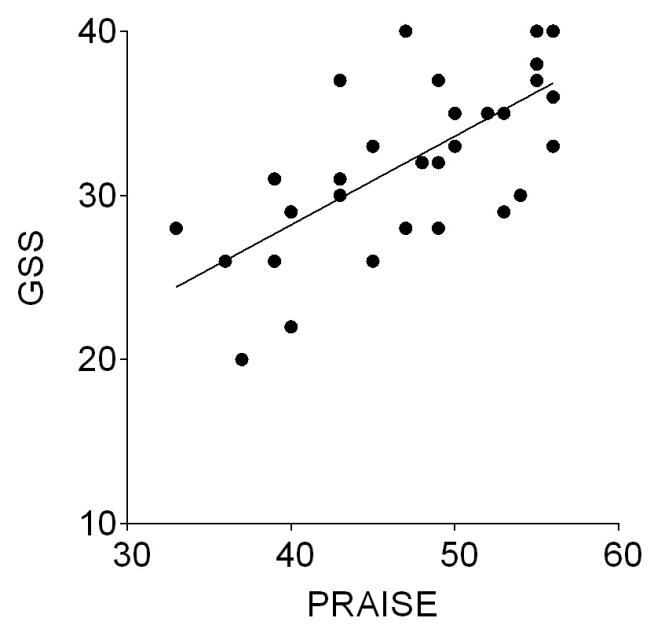

B

$r=0.346 ; p=0.04$

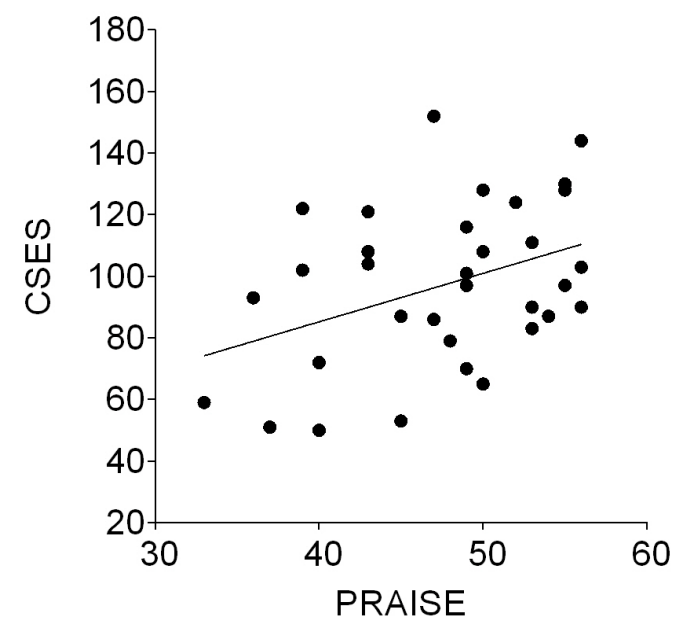

Figure 2. Correlation between PRAISE and (A) General Self-Efficacy Scale (GSS) and (B) COPD Self-Efficacy Scale (CSES).

with change detection, i.e., improvement or worsening, over a period of time or even after an intervention.

The validity was demonstrated through the significant correlations between the score of the Brazilian version of the PRAISE scale with the scores of GSS $(r=0.67 ; \mathrm{p}<0.01)$ and CSES $(r=0.35 ; \mathrm{p}<0.04)$, since both assess general and specific self-efficacy, respectively. The correlation with GSS was expected, since 10 items of the PRAISE scale come from GSS, and therefore, these questions are very similar to each other ${ }^{13}$. Conversely, CSES provides items with sufficient complexity in relation to specific situations of trust and disease management in patients with $\mathrm{COPD}^{9}$. PRAISE, in turn, addresses PR-related issues ${ }^{13}$ and complements the self-efficacy assessment of patients with COPD. Besides, it is established in the SCT that self-efficacy should be addressed in a very specific way rather than in general. So, using both scales is worth consideration, as they make the assessment more comprehensive and robust.
In this study, the association of PRAISE with the Resilience Scale was moderate $(r=0.53 ; \mathrm{p}<0.01)$. The assessment of resilience has been incorporated into the studies given its effects on health behavior and its influence on COPD patients' ability to manage the disease $\mathrm{e}^{32,33}$.

The association of the scores of the PRAISE scale with the scores of symptoms of anxiety and depression was similar to the scores found in the original study of the scale $(\mathrm{r}=-0.36$; $\mathrm{p}<0.001 ; \mathrm{r}=-0.37 ; \mathrm{p}<0.001$, respectively). Also, other studies have already demonstrated that increasing self-efficacy in patients with COPD is associated with fewer symptoms of anxiety and depression ${ }^{34-36}$.

PRAISE also showed a correlation with quality of life in the present study, which had been previously demonstrated ${ }^{37}$. Self-efficacy is an important construct in self-management and seems to contribute to health behavior and disease control ${ }^{6,38}$. 
A

$r=0.393 ; p=0.02$

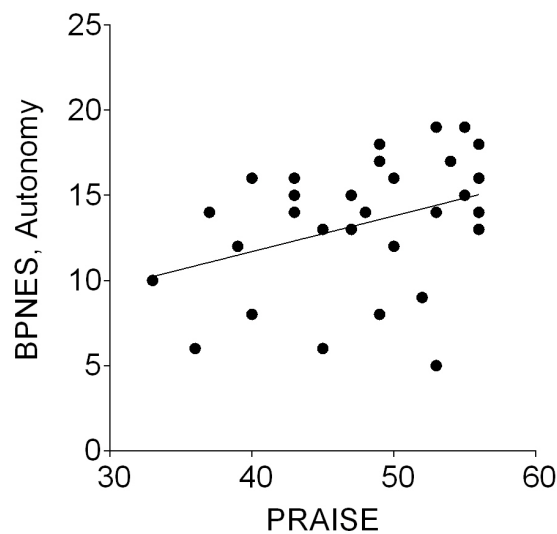

C

$r=0.530 ; p<0.01$

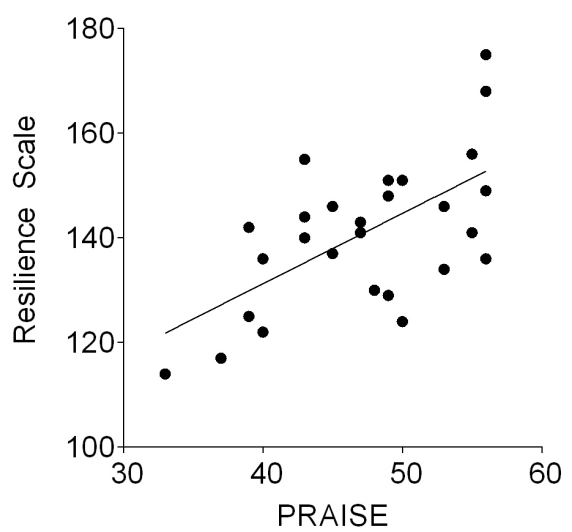

E

$r=-0.376 ; p=0.03$

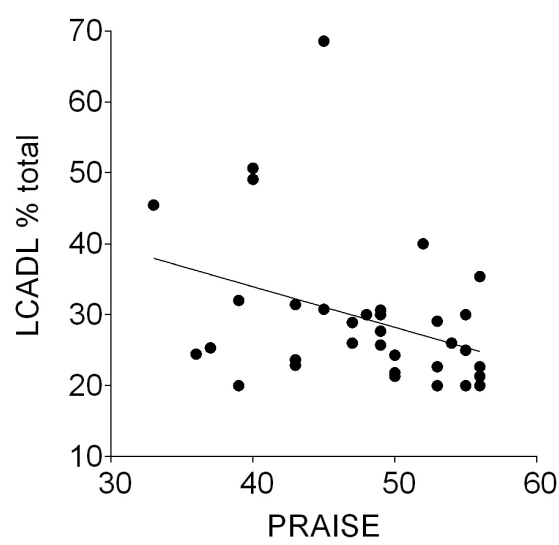
$r=0.363 ; p=0.03$

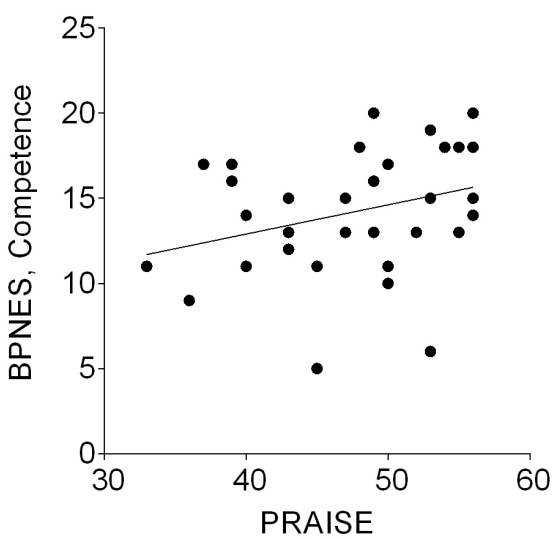

D

$r=-0.450 ; p<0.01$

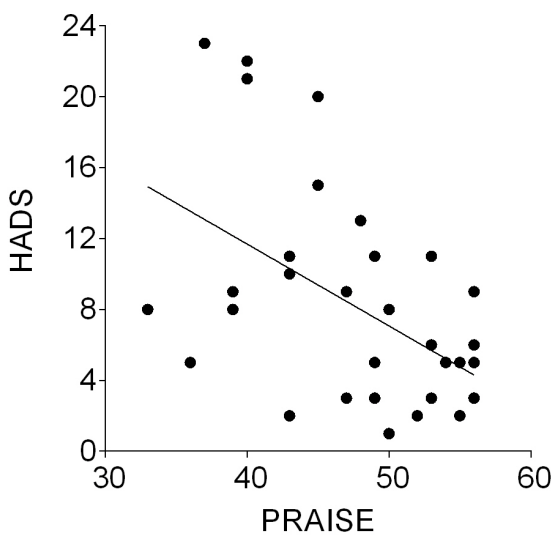

$\mathrm{F}$

$r=-0.420 ; p=0.01$

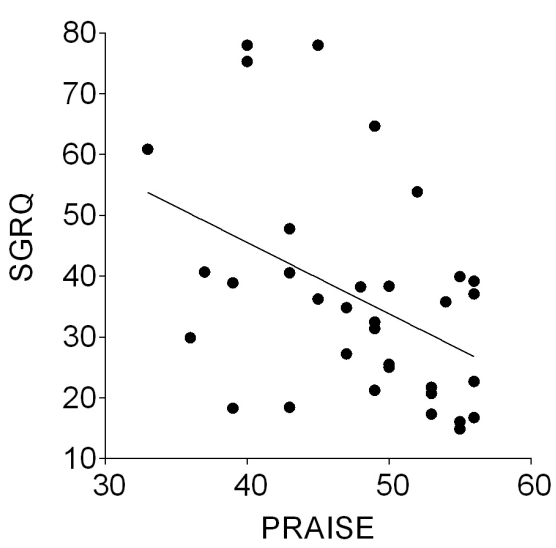

Figure 3. Correlation between PRAISE and (A) domain Autonomy of the Basic Psychological Needs in Exercise Scale (BPNES ${ }_{\text {Autonomy }}$ ); (B) domain Competence of the Basic Psychological Needs in Exercise Scale (BPNES Competence $_{1}$ ); (C) Resilience Scale; (D) total of Hospital Anxiety and Depression Scale $\left(\mathrm{HADS}_{\text {total }}\right)$; (E) total of London Chest Activity of Daily Living (LCADL\% ${ }_{\text {total }}$ ); (F) total of Saint George's Respiratory Questionnaire (SGRQ).

Regarding the Autonomy and Competence domains of the BPNES, studies have reported a positive association of fulfillment of basic psychological needs, motivation, selfefficacy and maintenance of behavior with better health outcomes $^{37}$, such as adherence and maintenance of physical activity programs ${ }^{38}$. They are seen as necessary nutrients for psychological health that individuals try to satisfy, and their satisfaction can affect many psychological factors, including self-efficacy ${ }^{38,39}$.

Ultimately, PRAISE was related to the functional limitation in activities of daily living. A similar result was demonstrated in a study that pointed out that the baseline score 
of the scale was predictive of changes in sedentary time after $\mathrm{PR}^{16}$. The association of the PRAISE score with functional status variables is important, as the scale can be used as a tool to identify patients who are more likely to improve the level of physical activity after PR.

The self-efficacy assessment should be used to consider people's needs and adapt PR to their needs ${ }^{40}$. Thus, selfefficacy can be better evaluated and understood with the PRAISE scale. This outcome has become more evident as a possible contribution and an opportunity to fill an important gap in PR. This is related to the process of behavior changes of patients and aims to ensure maintenance of physical activity and subsequent benefits of PR in the long run ${ }^{8}$. PR needs to be able to promote improvement in physical aspects as well as behavioral change in patients. Accordingly, one single approach cannot be applied to everyone. Protocols should consider the profile of self-efficacy and motivation of each patient, since personal factors create positive learning experiences, which will eventually improve self-efficacy ${ }^{8,12,40}$.

Despite the relevant findings of this study, the interpretability of the PRAISE scale still needs to improve. Even knowing that higher scores represent greater selfefficacy, so far there is no cutoff point, which is something important to be established. The present study did not evaluate responsiveness and minimum important difference. So, further studies are needed to investigate the ability of the Brazilian Portuguese version of the PRAISE scale to detect changes after PR and improve its response-to-intervention interpretation. In addition, the present study did not include patients with the less severe stage of COPD (GOLD stage I), compromising the extrapolation of the previous findings for those patients.

The PRAISE scale proved to be valid and reliable for assessing self-efficacy in patients with COPD in Brazil. Furthermore, self-efficacy correlated with other affectivecognitive outcomes such as resilience, symptoms of anxiety and depression, and the basic psychological needs of autonomy and competence, besides quality of life. Our findings make a significant contribution to clinical practice and research, as they enable the assessment of self-efficacy and facilitate the development of specific strategies in PR. Further research is necessary to establish the other measurement properties of the PRAISE.

\section{Funding}

This study was supported by the Fundação de Amparo à Pesquisa e Inovação do Estado de Santa Catarina, FAPESC/ Brazil (PAP UDESC, Chamada Pública Nº 04/2018, Termo de Outorga 2019TR658). Ms Karloh received a research grant from the Research Productivity Program (Estácio University Center, São José, Santa Catarina, Brazil).

\section{Conflict of interest}

None.

\section{References}

1. Agusti AG, Noguera A, Sauleda J, Sala E, Pons J, Busquets X. Systemic effects of chronic obstructive pulmonary disease. Eur Respir J. 2003;21(2):347-60. http://dx.doi.org/10.1183/09031936.03.004057 03. PMid:12608452.

2. Singh G, Zhang W, Kuo YF, Sharma G. Association of Psychological Disorders With 30-Day Readmission Rates in Patients With COPD. Chest. 2016;149(4):905-15. http://dx.doi.org/10.1378/chest.15-0449. PMid:26204260.

3. Spruit MA, Pitta F, McAuley E, ZuWallack RL, Nici L. Pulmonary rehabilitation and physical activity in patients with chronic obstructive pulmonary disease. Am J Respir Crit Care Med. 2015;192(8):924-33. http://dx.doi.org/10.1164/rccm.201505-0929CI. PMid:26161676.

4. Spruit MA, Singh SJ, Garvey C, ZuWallack R, Nici L, Rochester $\mathrm{C}$, et al. An official American Thoracic Society/European Respiratory Society statement: key concepts and advances in pulmonary rehabilitation. Am J Respir Crit Care Med. 2013;188(8):e13-64. http:// dx.doi.org/10.1164/rccm.201309-1634ST. PMid:24127811.

5. Bandura A. Self-efficacy: the exercise of control. W H Freeman; 1997.

6. Bourbeau J, Nault D, Dang-Tan T. Self-management and behaviour modification in COPD. Patient Educ Couns. 2004;52(3):271-7. http:// dx.doi.org/10.1016/S0738-3991(03)00102-2. PMid:14998597.

7. Bentsen SB, Wentzel-Larsen T, Henriksen AH, Rokne B, Wahl AK. Self-efficacy as a predictor of improvement in health status and overall quality of life in pulmonary rehabilitation--an exploratory study. Patient Educ Couns. 2010;81(1):5-13. http://dx.doi.org/10.1016/j. pec.2009.11.019. PMid:20356700.

8. Karloh M, Matias TS, Gavenda SG, Silveira JA. Novas perspectivas para a reabilitação pulmonar: contribuições teóricas da autoeficácia. In: J. M, M. K, Dal Corso SO, editors. PROFISIO - Programa de Atualização em Fisioterapia Cardiovascular e Respiratória. 5. ed. Porto Alegre: Artmed Panamericana; 2019. p. 9-32.

9. Awotidebe TO, Awopeju OF, Bisiriyu LA, Ativie RN, Oke KI, Adedoyin RA, et al. Relationships between respiratory parameters, exercise capacity and psychosocial factors in people with chronic obstructive pulmonary disease. Ann Phys Rehabil Med. 2017;60(6):387-92. http:// dx.doi.org/10.1016/j.rehab.2017.06.005. PMid:28797622.

10. Garrod R, Marshall J, Jones F. Self efficacy measurement and goal attainment after pulmonary rehabilitation. Int J Chron Obstruct Pulmon Dis. 2008;3(4):791-6. http://dx.doi.org/10.2147/COPD.S3954. PMid:19281094.

11. Oka RK, Gortner SR, Stotts NA, Haskell WL. Predictors of physical activity in patients with chronic heart failure secondary to either ischemic or idiopathic dilated cardiomyopathy. Am J Cardiol. 1996;77(2):159-63. http://dx.doi.org/10.1016/S0002-9149(96)905883. PMid:8546084

12. Karloh M, Sousa Matias T, Fleig Mayer A. Lack of responsiveness of the PRAISE tool to pulmonary rehabilitation: instrument or protocol limitation? Physiotherapy. 2020;106:215-6. http://dx.doi.org/10.1016/j. physio.2019.09.001. PMid:31992447.

13. Vincent E, Sewell L, Wagg K, Deacon S, Williams J, Singh S. Measuring a change in self-efficacy following pulmonary rehabilitation: an evaluation of the PRAISE tool. Chest. 2011;140(6):1534-9. http:// dx.doi.org/10.1378/chest.10-2649. PMid:21737490.

14. Santos CD, Santos AJ, Santos M, Rodrigues F, Barbara C. Pulmonary rehabilitation adapted index of self-efficacy (PRAISE) validated to Portuguese respiratory patients. Pulmonology. 2019;25(6):334-9. http:// dx.doi.org/10.1016/j.pulmoe.2019.06.003. PMid:31540750.

15. Song HY, Nam KA. Psychometric properties of the Korean version of the Pulmonary Rehabilitation Adapted Index of Self-Efficacy (PRAISE) for individuals with COPD. Int J Chron Obstruct Pulmon Dis. 2017;12:2611-20. http://dx.doi.org/10.2147/COPD.S142488. PMid:28919729. 
16. Liacos A, McDonald CF, Mahal A, Hill CJ, Lee AL, Burge AT, et al. The Pulmonary Rehabilitation Adapted Index of Self-Efficacy (PRAISE) tool predicts reduction in sedentary time following pulmonary rehabilitation in people with chronic obstructive pulmonary disease (COPD). Physiotherapy. 2019;105(1):90-7. http://dx.doi.org/10.1016/j. physio.2018.07.009. PMid:30316548.

17. Beaton DE, Bombardier C, Guillemin F, Ferraz MB. Guidelines for the process of cross-cultural adaptation of self-report measures. Spine. 2000;25(24):3186-91. http://dx.doi.org/10.1097/00007632200012150-00014. PMid:11124735.

18. Mokkink LB, Terwee CB, Knol DL, Stratford PW, Alonso J, Patrick DL, et al. The COSMIN checklist for evaluating the methodological quality of studies on measurement properties: a clarification of its content. BMC Med Res Methodol. 2010;10(1):22. http://dx.doi. org/10.1186/1471-2288-10-22. PMid:20298572.

19. Schwarzer R, Jerusalem M. Generalized Self-efficacy scale. measures in health psychology: a user's portfolio causal and control beliefs. Windsor, UK: NFER-NELSON; 1995.

20. Rolim MKSB. Autoeficácia, estilo de vida e desempenho cognitivo de adolescentes ativos e sedentários. Florianópolis, SC: Universidade do Estado de Santa Catarina; 2007.

21. Wigal JK, Creer TL, Kotses H. The COPD self-efficacy scale. Chest. 1991;99(5):1193-6. http://dx.doi.org/10.1378/chest.99.5.1193. PMid:2019177.

22. Miller MR, Hankinson J, Brusasco V, Burgos F, Casaburi R, Coates A, et al. Standardisation of spirometry. Eur Respir J. 2005;26(2):319-38. http://dx.doi.org/10.1183/09031936.05.00034805. PMid:16055882.

23. Pereira CA, Sato T, Rodrigues SC. New reference values for forced spirometry in white adults in Brazil. Jornal brasileiro de pneumologia: publicacao oficial da Sociedade Brasileira de Pneumologia e Tisilogia. 2007;33(4):397-406

24. Jones PW, Quirk FH, Baveystock CM. The St George's Respiratory Questionnaire. Respiratory medicine. 1991;85(Suppl B):25-31; discussion 3-7.

25. Sousa TC, Jardim JR, Jones P. Validação do Questionário do Hospital Saint George na Doença Respiratória (SGRQ) em pacientes portadores de doença pulmonar obstrutiva crônica no Brasil. J Pneumol. 2000;26(3):119-28. http://dx.doi.org/10.1590/S010235862000000300004 .

26. Camelier A, Rosa FW, Salim C, Nascimento OA, Cardoso F, Jardim JR. Using the Saint George's Respiratory Questionnaire to evaluate quality of life in patients with chronic obstructive pulmonary disease: validating a new version for use in Brazil. Jornal Brasileiro de Pneumologia: publicacao oficial da Sociedade Brasileira de Pneumologia e Tisilogia. 2006;32(2):114-22.

27. Garrod R, Bestall JC, Paul EA, Wedzicha JA, Jones PW. Development and validation of a standardized measure of activity of daily living in patients with severe COPD: the London Chest Activity of Daily Living scale (LCADL). Respir Med. 2000;94(6):589-96. http://dx.doi. org/10.1053/rmed.2000.0786. PMid:10921765.

28. Carpes MF, Mayer AF, Simon KM, Jardim JR, Garrod R. The brazilian portuguese version of the London Chest Activity of Daily Living scale for use in patients with chronic obstructive pulmonary disease. Jornal brasileiro de pneumologia: publicacao oficial da Sociedade Brasileira de Pneumologia e Tisilogia. 2008;34(3):143-51.

29. Botega NJ, Bio MR, Zomignani MA, Garcia C Jr, Pereira WA. Mood disorders among inpatients in ambulatory and validation of the anxiety and depression scale HAD. Rev Saude Publica. 1995;29(5):355-63. PMid:8731275.

30. Phan T, Carter O, Adams C, Waterer G, Chung LP, Hawkins M, et al. Discriminant validity of the Hospital Anxiety and Depression Scale, Beck Depression Inventory (II) and Beck Anxiety Inventory to confirmed clinical diagnosis of depression and anxiety in patients with chronic obstructive pulmonary disease. Chron Respir Dis. 2016;13(3):220-8. http://dx.doi.org/10.1177/1479972316634604. PMid:26944070.

31. Vlachopoulos SP, Michailidou S. Development and initial validation of a measure of autonomy, competence, and relatedness in exercise: the basic psychological needs in exercise scale. Meas Phys Educ Exerc Sci. 2006;10(3):179-201. http://dx.doi.org/10.1207/ s15327841mpee1003 4.

32. Cannon DL, Sriram KB, Liew AW, Sun J. Resilience factors important in health-related quality of life of subjects with COPD. Respir Care. 2018;63(10):1281-92. http://dx.doi.org/10.4187/respcare.05935. PMid:30065078.

33. Bentsen SB, Wentzel-Larsen T, Henriksen AH, Rokne B, Wahl AK. Anxiety and depression following pulmonary rehabilitation. Scand J Caring Sci. 2013;27(3):541-50. http://dx.doi.org/10.1111/j.14716712.2012.01064.x. PMid:22924539.

34. Andenaes R, Bentsen SB, Hvinden K, Fagermoen MS, Lerdal A. The relationships of self-efficacy, physical activity, and paid work to health-related quality of life among patients with chronic obstructive pulmonary disease (COPD). J Multidiscip Healthc. 2014;7:239-47. http://dx.doi.org/10.2147/JMDH.S62476. PMid:24944515.

35. Solano JP, Gomes B, Higginson IJ. A comparison of symptom prevalence in far advanced cancer, AIDS, heart disease, chronic obstructive pulmonary disease and renal disease. J Pain Symptom Manage. 2006;31(1):58-69. http://dx.doi.org/10.1016/j. jpainsymman.2005.06.007. PMid:16442483.

36. Lopes AC. Estratégias para avaliação do paciente DPOC grave e muito grave. São Paulo: Faculdade de Medicina da USP; 2016.

37. Ryan RM, Deci EL. Intrinsic and extrinsic motivations: classic definitions and new directions. Contemp Educ Psychol. 2000;25(1):5467. http://dx.doi.org/10.1006/ceps.1999.1020. PMid:10620381.

38. Edmunds J, Ntoumanis N, Duda JL. Testing a self-determination theory-based teaching style intervention in the exercise domain. Eur J Soc Psychol. 2008;38(2):375-88. http://dx.doi.org/10.1002/ejsp.463.

39. Guimaraes SER, Boruchovitch E. O estilo motivacional do professor e a motivação intrínseca dos estudantes: uma perspectiva da teoria da autodeterminação. Psicol Reflex Crit. 2004;17(2):143-50. http://dx.doi. org/10.1590/S0102-79722004000200002.

40. Karloh M, Martias TS, Silveira JA, Gavenda SG. Novas perspectivas para a reabilitação pulmonar: Uma abordagem baseada na motivação. In: Martins J, Karsten M, Dal Corso S, editors. PROFISIO - Programa de Atualização em Fisioterapia Cardiovascular e Respiratória. 5. ed. Porto Alegre: Artmed Panamericana; 2019. p. 79-112. 


\section{Author contribuitions}

All authors contributed to the drafting of the manuscript. M.K, T.S.M, and A.F.M contributed to the study design and protocol. M.K., S.G.G., H.F.A. contributed to the data acquisition process.M.K, S.G.G., T.S.M and A.F.M contributed to the data analysis and statistical support. M.K, T.S.M and A.F.M contributed to the critical revision of the manuscript. A.F.M. is the guarantor of the paper, taking responsibility for the integrity of the work as a whole, from inception to the published article.

\section{Author information}

\section{Simone Graciosa Gavenda}

Graduated in Physiotherapy, Universidade do Vale do Itajaí, Brazil. MSc in Physiotherapy, Universidade do Estado de Santa Catarina, Brazil. Adjunct Professor, Centro Universitário IDEAU, Brazil.

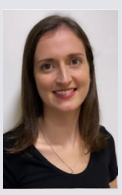

\section{Manuela Karloh}

Graduated in Physiotherapy, Universidade do Estado de Santa Catarina, Brazil. PhD in Medical Sciences, Universidade Federal de Santa Catarina, Brazil. Adjunct Professor, Department of Physiotherapy, Universidade do Estado de Santa Catarina, Brazil. Adjunct Professor, Centro Universitário Estacio, Brazil.

\section{Thiago Sousa Matias}

Graduated in Physical Education, Universidade do Estado de Santa Catarina, Brazil. PhD in Human Movement Sciences, Universidade do Estado de Santa Catarina, Brazil. Adjunct Professor, School of Sports, Universidade Federal de Santa Catarina

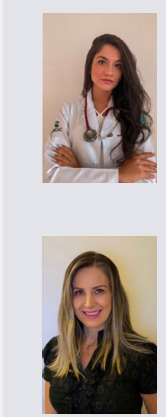

\section{Hellen Fontão Alexandre}

Graduated in Physiotherapy, Universidade do Estado de Santa Catarina, Brazil. MSc in Physiotherapy, Universidade do Estado de Santa Catarina. PhD student, Programa de Pós-Graduação em Ciências Médicas, Universidade Federal de Santa Catarina, Brazil.

\section{Anamaria Fleig Mayer}

Graduated in Physiotherapy, Universidade Federal de Santa Maria, Brazil. PhD Ciências da Reabilitação, Universidade Federal de São Paulo.

Associate Professor, Department of Physiotherapy, Universidade do Estado de Santa Catarina, Brazil. Coordinator Núcleo de Assistência, Ensino e Pesquisa em Reabilitação Pulmonar (NuReab), Universidade do Estado de Santa Catarina, Brazil. 